\title{
Turismo de observação de aves no PN Lagoa do Peixe: oportunidades ou ameaças?
}

\section{Birdwatching tourism at PN Lagoa do Peixe: opportunities or threats?}

Silvia Maria Kaiser, João Manuel dos Anjos Gonçalves, Luís Fernando Carvalho Perelló

RESUMO: Observadores de aves ou "birdwatchers" podem integrar um nicho de mercado importante no âmbito do ecoturismo, contribuindo com o aporte econômico e conscientização ambiental. Observação de aves tornou-se um segmento do turismo de natureza, constituindo um mercado especializado. No Brasil, o "birdwatching" atrai turistas para mais de 50 destinos. Hoje existe em torno de 37 mil observadores de aves no Brasil e a atividade tem crescido exponencialmente. Estima-se que nos últimos dez anos houve um incremento de $1.650 \%$ neste número e a maioria dos observadores está vinculada à plataforma colaborativa WikiAves. O Brasil figura entre um dos mais importantes destinos para quem quer praticar a observação de aves. Neste estudo foi investigado se os observadores de aves reúnem perfil socioeconômico capaz de alavancar uma cadeia de ecoturismo no litoral médio do Rio Grande do Sul, onde se localiza o Parque Nacional da Lagoa do Peixe. A pesquisa verificou qual o peso econômico que o turismo de "birdwatching" poderá ter na região. Também foram listadas as deficiências que os observadores de aves apontaram na estrutura turística local e o que sugerem para melhorá-la. Foi apurado se existem espécies mais assediadas e as ferramentas empregadas na observação, como o playback. A amostra pesquisada demonstrou que os observadores de aves que frequentam a região são pessoas em sua maioria já estabelecidas profissionalmente, com situação financeira estável e real capacidade de consumo. Demonstram preocupação com a sustentabilidade da atividade e sugerem a criação de normativas para regular a atividade na região. O trabalho concluiu que a categoria tem condições de ajudar na implantação de uma cadeia turística local.

PALAVRAS-CHAVE: Observação de aves; Parque Nacional; Birdwatching; Ecoturismo; Áreas Protegidas. 
ABSTRACT: Birdwatchers can integrate an important market niche within the scope of ecotourism, collaborating to the economic contribution and environmental awareness. Birdwatching has become a segment of nature tourism, constituting a specialized market. In Brazil, birdwatching attracts tourists to more than 50 destinations. Today there are around 37 thousand birdwatchers in Brazil and the activity has grown exponentially. It is estimated that in the last ten years there has been an increase of $1,650 \%$ in this number and most of the observers are linked to the collaborative platform WikiAves. Brazil is one of the most important destinations for those who want to practice birdwatching. In this study, it was investigated whether birdwatchers have a socioeconomic profile capable of leveraging an ecotourism chain on the middle coast of Rio Grande do Sul, where the Lagoa do Peixe National Park is located. The survey verified the economic weight that birdwatching tourism may have in the region. Also listed were the deficiencies that birdwatchers pointed out in the local tourist structure and what they suggest to improve it. It was determined whether there are more harassed species and the tools used in observation, such as playback. The researched sample demonstrated that the birdwatchers that frequent the region are mostly professionally established people, with a stable financial situation and real consumption capacity. They show concern for the sustainability of the activity and suggest the creation of regulations to normatize the activity in the region. The work concluded that the category is able to help in the implantation of a local tourist chain.

KEYWORDS: Birdwatching; National Park; Birdwatching; Ecotourism; Protected Areas.

\section{Introdução}

O turismo mundial superou as expectativas de crescimento no ano de 2017, com 1 bilhão de viajantes internacionais. Esse aumento de 7\% em comparação com o ano de 2016, representou o melhor resultado em sete anos (MTUR, 2020). Dentre os motivos para tal crescimento, a Organização Mundial do Turismo (OMT) aponta o ecoturismo como um dos segmentos que mais contribuíram para o incremento do setor, sendo uma das categorias mais promissoras, inclusive no Brasil.

As chegadas de turistas internacionais cresceram $4 \%$ entre janeiro e setembro de 2019 em comparação com o mesmo período do ano anterior, com desempenho misto entre as regiões do mundo, segundo a "World Turism Organization" (UNTWO, 2020). Porém em 2020 houve a redução de $60 \%$ a $80 \%$ no número de turistas internacionais em decorrência da pandemia de COVID-19. No "Global Guidelines to Restart Turism", divulgado pela OMT em maio de 2020, as orientações para retomada do turismo destacam a oportunidade de criar novas experiências por meio de produtos segmentados e mais individualizados, focados no ecoturismo, cultura, esporte, turismo rural e rotas locais (MTUR, 2020).

O ecoturismo ganhou impulso a partir da década de 90, com o fortalecimento da ideia de desenvolvimento sustentável. Essa categoria do turismo é definida como "viagem responsável para áreas naturais, que conserva o meio ambiente e promove o bem-estar da comunidade local", conforme a Sociedade Internacional do Ecoturismo (TIES, 2015). O turismo em áreas protegidas, uma opção de ecoturismo, ainda é carente de estatísticas precisas, mas de modo geral a visitação a esses ambientes vem aumentando globalmente em países que abrigam grandes sistemas de espaços 
protegidos, incluindo a Ásia, América do Sul e África, bem como alguns países da Europa (PICKERING et.al., 2018).

Até a década de 1980, as áreas protegidas eram vistas como lugar de lazer e contemplação com um forte componente de risco ambiental. Visitação e preservação apareciam como atividades antagônicas. O turismo, principalmente o chamado "turismo de massa", não era bem-visto, porém entendido como necessário. Com o ecoturismo, o atrativo das áreas protegidas passou a ser a natureza preservada, em lugar da beleza da paisagem. Assim, a proteção em si adquiriu um valor econômico, e não apenas ambiental (GORINI, et.al., 2006).

\section{Visitação e resultados econômicos}

O segmento que envolve o ecoturismo e outras formas de turismo relacionadas à natureza já representa aproximadamente $20 \%$ do total de viagens internacionais segundo a "The International Ecoturism Society", TIES (2000). O impacto econômico do turismo em áreas protegidas enfatiza sua importância comunitária, regional e nacional (Eagles et al., 2002). O uso público contribui também para a educação ambiental dos visitantes, fazendo do turismo um elemento importante para a operação e manutenção dos parques nacionais (SEMEIA, 2015).

Os segmentos de turismo que podem estar associados a experiência na natureza são:

a) turismo de aventura: atividade que pressupõe uma programação participativa, na qual o turista passa a ser protagonista, envolvendo diferenciados níveis de risco e imprevistos. Algumas das atividades desta modalidade são caminhadas ("trekking"), canoagem ("canoeing"), ciclismo ("cycling"), mergulho ("diving");

b) turismo ecológico, turismo verde ou turismo de natureza: viagens a espaços naturais, motivadas pelo desejo/necessidade de contato com a natureza, observação passiva da flora, fauna, paisagem e aspectos cênicos do entorno e/ou interação com meio natural; e

c) ecoturismo: viagens a espaços naturais delimitados e protegidos pelo Estado ou iniciativa privada. Pressupõe sempre uma utilização controlada da área, com planejamento de uso sustentável de seus recursos naturais e culturais por meio de estudos de impacto ambiental, estimativas da capacidade de carga e suporte do local, monitoramento e avaliação constantes, com plano de manejo e sistema de gestão responsável.

Essas atividades podem gerar receitas econômicas para áreas protegidas e comunidades locais por conta dos gastos feitos pelos visitantes e pelos recursos advindos das concessões comerciais (Balmford et al., 2015). As receitas são geradas desde a cobrança de ingressos que os turistas pagam para usufruir das atrações ou serviços até com os gastos que fazem na comunidade local com hospedagem, compra de "souvenirs", pagamentos de guias e gastronomia.

Em artigo publicado na revista PLOS Biology em 2015, Balmford e outros pesquisadores compilaram um banco de dados globalmente representativo de visitas a áreas protegidas (AP) e construíram modelos específicos para AP terrestres. Esses modelos previram as taxas de visita conforme tamanho da AP, tamanho da população local, distância, atratividade natural e renda nacional. A aplicação desses modelos a todos, exceto as menores AP terrestres do mundo sugerem que juntas elas recebem cerca de 8 bilhões de visitas / ano - dos quais mais de $80 \%$ estão na Europa e América 
do Norte. Essas visitas geram aproximadamente US \$ 600 bilhões/ano em gastos diretos no país e US $\$ 250$ bilhões/ano em excedente do consumidor (BALMFORD et al., 2015). Gastos diretos são aqueles relacionados com pagamentos de taxas, transporte e alojamento. Excedente do consumidor são os gastos realizados pelos turistas além do que é considerado necessário.

O aumento no turismo de natureza é fenômeno que se constata em todos os continentes. A Austrália possui mais de 10.500 áreas protegidas, cobrindo 19,63\% do território - mais de 150 milhões de hectares. Em 2009, o setor de turismo baseado na natureza contribuiu com mais de AU\$ 33 bilhões para a economia australiana. Foram mais de 28 milhões de visitantes e o turismo representou naquele ano $9,6 \%$ das vagas de trabalho, superando a marca de 200 mil empregos (DEPARTMENT OF AGRICULTURE, WATER AND THE ENVIRONMENT, 2019).

$\mathrm{Na}$ América do Norte, desde o ártico canadense até as florestas tropicais do México, somam-se mais de 45 mil áreas terrestres e marinhas protegidas. No México, a Comissão Nacional de Áreas Naturais Protegidas estima que cerca de 5,5 milhões de turistas visitam anualmente as 176 áreas protegidas do país (ARIZPE et.al., 2013).

Na Europa países como como a França, (PICKERING, et.al., 2018), Espanha e Alemanha destacam-se entre os que recebem viajantes com foco no turismo de natureza. Alemanha constatou, em pesquisa realizada em 2007 junto aos turistas que frequentavam parques nacionais, que 51 milhões de visitantes geravam um volume de negócios de 2,1 milhões de €/ano, segundo a Federal Agency for Nature Conservation (BFN).

Lugares como o leste da Ásia apresentam crescimento do turismo, percebido no aumento das viagens e visitas a áreas protegidas (MCCOOL, 2009). Entre os anos de 2014 e 2018, destinos da Ásia-Pacífico tiveram aumento de quase $24 \%$ na chegada de turistas internacionais (PATA, 2019).

Na Argentina, a Fundación Vida Silvestre Argentina (FVSA) constatou junto aos operadores de turismo, que cerca de $50 \%$ dos visitantes do país chegaram atraídos por seus parques nacionais no ano de 2005 . O mesmo estudo revelou que $19 \%$ dos operadores turísticos da Argentina trazem contingentes especialmente interessados nas belezas naturais conservadas dentro das áreas protegidas (Gorini et al., 2006).

No Brasil, entre os anos de 2014 e 2015, houve acréscimo de 3\% de estrangeiros que viajaram a lazer ao país motivados pelos atrativos naturais, ecoturismo e turismo de aventura (MTUR 2016). Em 2019, turistas estrangeiros gastaram no Brasil US \$ 5,9 bilhões. E no primeiro trimestre de 2020 , mesmo com a pandemia, o turismo estrangeiro movimentou US \$1,4 bi no país (MTUR 2019).

Nesse contexto, o ecoturismo aparece como uma oportunidade de geração de trabalho e renda para comunidades locais. A implementação do ecoturismo estimula a aplicação de práticas sustentáveis aos demais segmentos da indústria do turismo, mantendo as tradições do lugar e dos seus moradores (SPAOLONSE; MARTINS, 2017), permitindo que a receita advinda da atividade permaneça na comunidade (TIES, 2019). 


\section{O turismo de observação de aves}

Os observadores de aves ou "birdwatchers" constituem um nicho de mercado importante no âmbito do ecoturismo, contribuindo com o aporte econômico e conscientização ambiental. Na medida em que os moradores das comunidades locais são envolvidos em atividades de apoio, o aspecto social também é beneficiado nesta integração (SILVA-MELO et. al., 2019). A observação de aves é uma atividade consolidada, mas ainda com muito espaço para crescer, conforme trabalhos publicados nos últimos anos (ALMEIDA et al. 2016; PINHEIRO, 2019; SILVA, 2020).

Observação de aves tornou-se um segmento do turismo de natureza, constituindo um mercado turístico especializado. Historicamente dominado por britânicos e norte-americanos, está se tornando mais diversificado, com o aumento do interesse de mercados asiáticos, como China, Japão e Índia (STEVEN; JONES, 2014).

Nos Estados Unidos, mais de 46 milhões de americanos são praticantes da atividade de observação de aves (FWS, 2013). Esses turistas, em 2016, contribuíram com quase US\$ 80 bilhões para a economia do país. Segundo o Departamento de Agricultura dos Estados Unidos (USDA), a atividade recreativa com maior crescimento entre 1982 e 2009 foi a observação e registro fotográfico de aves, com o aumento de $287 \%$ no período. Além disso, a atividade de observação de aves nos Estados Unidos gera 600 mil empregos (SEBRAE, 2018).

$\mathrm{Na}$ Europa, três em cada dez pessoas são observadoras de aves e no Reino Unido existem cerca de dois milhões de praticantes (LAMAS et.al., 2018). Na rota das aves migratórias da Ásia para a Europa, são registrados dez milhões de observadores cadastrados e atuantes $(\mathrm{Cl}, 2017)$. Já na Espanha, o Parque Nacional de Monfrague recebe 300 mil visitantes/ano para prática de observação de aves (SEBRAE, 2018).

No Brasil, o "birdwatching" atrai turistas para mais de 50 destinos de ecoturismo. Esses locais distribuídos de norte a sul do país recebem grupos para observação de aves com roteiros definidos (VALADARES, 2016). Os lugares mais visados localizam-se na Amazônia e no Pantanal, além do Parque Nacional de Foz do Iguaçu (DIAS; FIGUEIRA, 2010).

Hoje existem mais de 30 mil observadores de aves no Brasil e a atividade tem crescido exponencialmente. Estima-se que nos últimos 10 anos houve um incremento de $1.650 \%$ neste número (SEBRAE, 2018). A plataforma colaborativa WikiAves reúne os observadores de aves brasileiros. Entre outubro de 2019 e marco de 2021 a plataforma registrou um crescimento no seu quadro de associados de $15 \%$, atingindo mais de 37 mil observadores.

O Brasil figura entre um dos mais importantes destinos para quem quer praticar a observação de aves. Possui grande heterogeneidade ambiental, o que garante uma riqueza de avifauna. São quase duas mil espécies, algumas muito raras e pelo menos 166 globalmente ameaçadas de extinção (SEBRAE, 2018).

Este estudo teve como objetivo examinar se os observadores de aves reúnem perfil socioeconômico capaz de auxiliar a alavancagem de uma cadeia de ecoturismo no litoral médio do Rio Grande do Sul, tendo como um dos principais destinos o Parque Nacional da Lagoa do Peixe.

Para tanto, a pesquisa procurou responder quatro perguntas: 
1. Qual o peso econômico que o turismo de "birdwatching" poderá ter na região do

Parque Nacional da Lagoa do Peixe?

2. Quais as deficiências que os observadores de aves apontam na estrutura turística local?

3. Existe na região do Parque Nacional da Lagoa do Peixe uma cadeira turística de "birdwatching" organizada?

4. O turismo de "birdwatching" como vem sendo realizado hoje na região está focado em poucas espécies, algumas das quais vulneráveis ao assédio humano?

\section{Material e Métodos}

\section{Caracterização da área de estudo}

O Parque Nacional da Lagoa do Peixe (Figura 1) foi criado em 1986 com o objetivo de garantir a integridade dos ecossistemas litorâneos, das aves residentes e das migratórias, que dependem desses ambientes para seu ciclo vital. Situado entre a Laguna dos Patos e o Oceano Atlântico ( $\left.31^{\circ} 14^{\prime} \mathrm{S}, 50^{\circ} 57^{\prime} \mathrm{W}\right)$, sua área abrange $367,16 \mathrm{~km}^{2}$ e abriga uma variedade de aves aquáticas, terrestres, residentes e migratórias, associadas à diversidade de habitats costeiros (GUADAGNIN et al., 2005).

É um sítio Ramsar e Zona Núcleo da Reserva da Biosfera da Mata Atlântica. Desde 1991 integra a Rede Hemisférica de Reservas de Aves Limícolas pela "International Association of Fish Wildlife Agency", na categoria de Reserva Internacional. O parque tem o reconhecimento internacional como Área Importante para a Conservação das Aves.

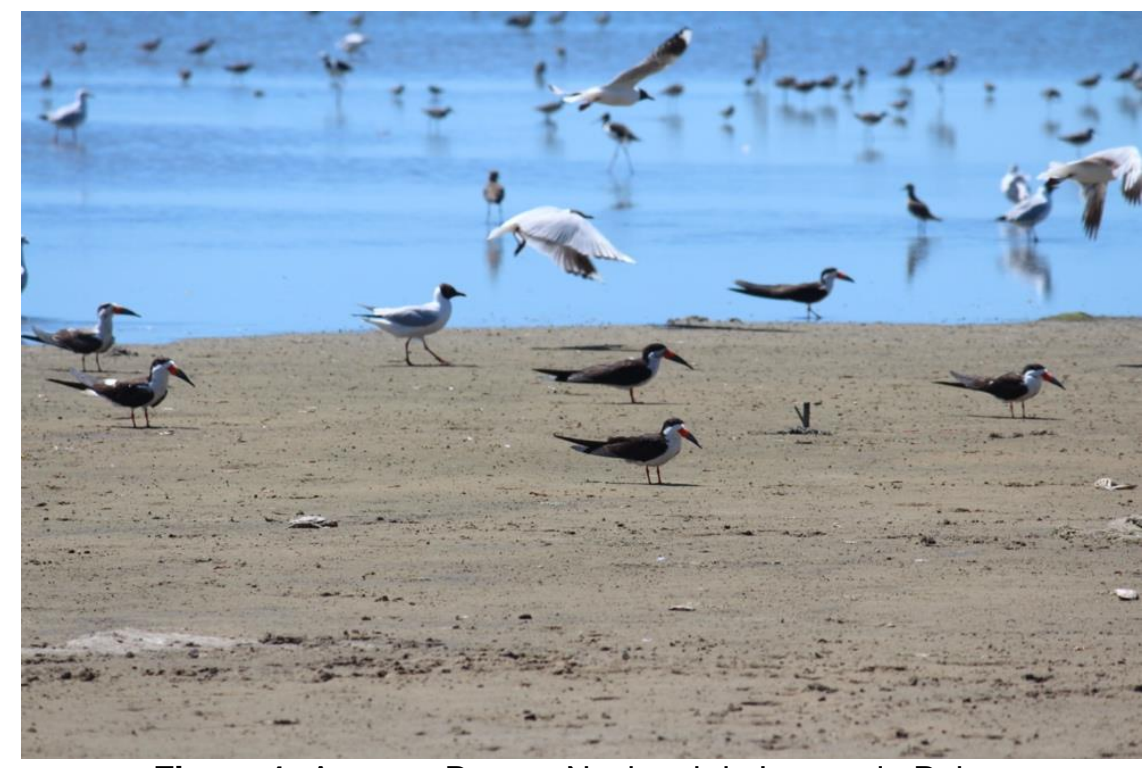

Figura 1: Aves no Parque Nacional da Lagoa do Peixe.

Figure 1: Birds at Lagoa do Peixe National Park.

Fonte: Autores (2021).

Source: Authors (2021).

Sua paisagem é composta por mata de restinga, banhados, campos de dunas, marismas, lagoas de água doce e salobra, além de praias e uma área marinha costeira arenosa (Figura 2). Está localizado nos municípios de Mostardas e Tavares, no Litoral 
Médio do estado do Rio Grande do Sul, Brasil, sendo que toda a região no entorno do Parque se insere na planície costeira do Estado, em sua maior parte ocupada por um sistema de lagoas (TOMAZELLI, VILLWOCK, 1991).

A economia da região historicamente é movida pela orizicultura irrigada e pecuária. A silvicultura foi introduzida na década de 1970 e, mais recentemente a região tem se revelado importante para a geração de energia eólica em razão de seu regime de ventos. A pesca artesanal é exercida na região que abriga ainda uma comunidade quilombolas. Mostardas e Tavares possuíam somente 18,4\% e 11,9\%, respectivamente, de população empregada em 2017, conforme dados do Instituto Brasileiro de Geografia e Estatística (IBGE, 2017).

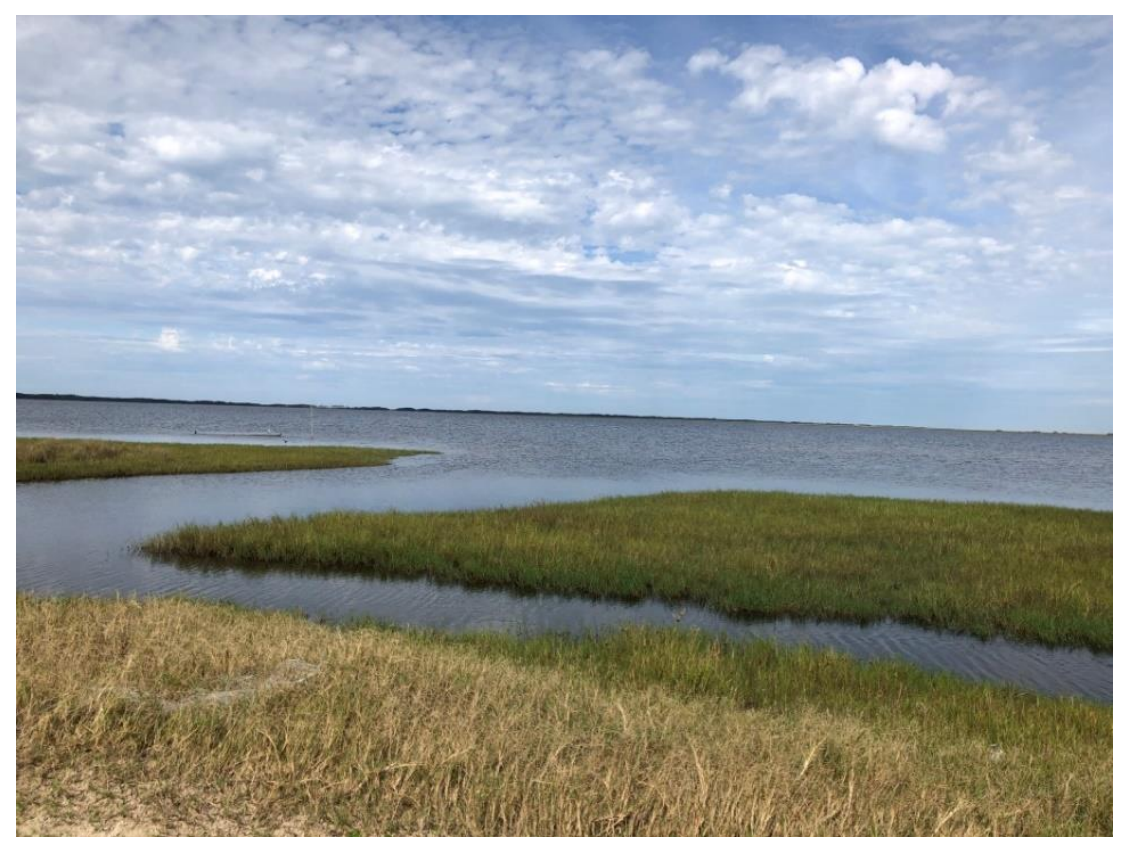

Figura 2: Lagoa do Peixe.

Figure 2: Lagoa do Peixe.

Fonte: Autores (2021).

Source: Authors (2021).

\section{Método}

Para examinar se os observadores de aves possuem perfil socioeconômico capaz de auxiliar a alavancagem de uma cadeia de ecoturismo na região do Parque Nacional da Lagoa do Peixe foi aplicado um questionário aos observadores de aves. Foram selecionados 553 observadores de aves que registraram na plataforma WikiAves algum avistamento de ave em pelo menos um dos municípios que abrangem o Parque Nacional da Lagoa do Peixe. O link enviado deu acesso online à plataforma Google Forms, onde os observadores registraram suas respostas. O questionário ficou disponível durante 55 dias, entre abril e maio de 2019.

As respostas foram tabuladas em base Excel, representadas em gráficos e tabelas. Para fins de organização das respostas o questionário foi dividido em três blocos: a) Perfil dos observadores de aves; b) Potencial turístico da atividade de observação de aves e c) Impacto ambiental potencial da observação de aves. Durante a pesquisa foram realizadas três idas a campo. 


\section{Resultados}

\section{Perfil do observador de aves}

Dos 553 questionários encaminhados, 253 retornaram (45,7\%). No universo dos respondentes, 84,1\% pertencem ao gênero masculino. Dos 251 que informaram a idade, mais de $50 \%$ situam-se na faixa etária entre 41 e 60 anos e $82,9 \%$ (210 respondentes) possuem curso superior, sendo $43 \%$ com pós-graduação.

A principal atividade laboral dos entrevistados se dá no setor privado $(34,8 \%)$, seguidos pelos trabalhadores do setor público $(22,1 \%)$, percentual idêntico cabe aos aposentados (22,1\%). Além disso, dos respondentes, $41,9 \%$ possuem renda familiar em torno de $R \$ 10.000,00$ (equivalente a US $\$ 2.500,00$ - câmbio de abril/2019 - $R \$$ $3,86=U \$ 1,00)$. Mais de $69 \%$ dos entrevistados têm renda familiar acima de seis mil reais (Figura 3 ).

Qual a renda do grupo familiar:

253 respostas

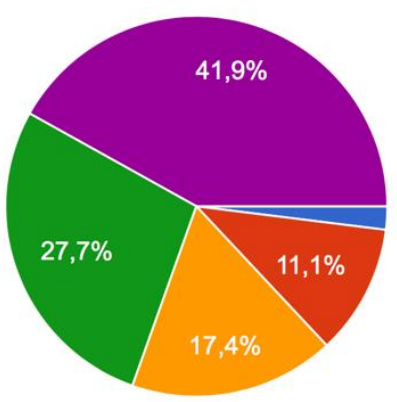

Ate $\mathrm{R} \$ 2.000,00$

De $R \$ 2.001,00$ a $R \$ 4.000,00$

De R\$ 4.001,00 a R\$ 6.000,00

De $R \$ 6.001,00$ a $R \$ 10.000,00$

+ de $R \$ 10.000,00$

Figura 3: Distribuição percentual dos observadores de aves quanto a renda familiar.

Figure 3: Percentage distribution of bird watchers in terms of family income.

Fonte: Elaborado pelos autores (2021).

Source: Elaborated by the authors (2021).

Os observadores de aves cadastrados no WikiAves que responderam o questionário e frequentaram o Parque Nacional da Lagoa do Peixe e região são exclusivamente brasileiros. Do total de respondentes, 48\% (122) residem na região Sul do Brasil (RS, SC e PR). Pouco mais de 30\% reside na região Sudeste, onde se encontra a maior renda per capita do país (IBGE, 2017). As regiões sul e sudeste abrigam quase $80 \%$ dos pesquisados.

A pesquisa mostrou que a atividade de observação de aves entre os entrevistados teve um crescimento importante a partir do ano 2000 , com destaque no período entre os anos 2009 e 2016, quando o maior percentual, de 66\% (167 pessoas), iniciou a prática de "birdwatching" (Figura 4). 


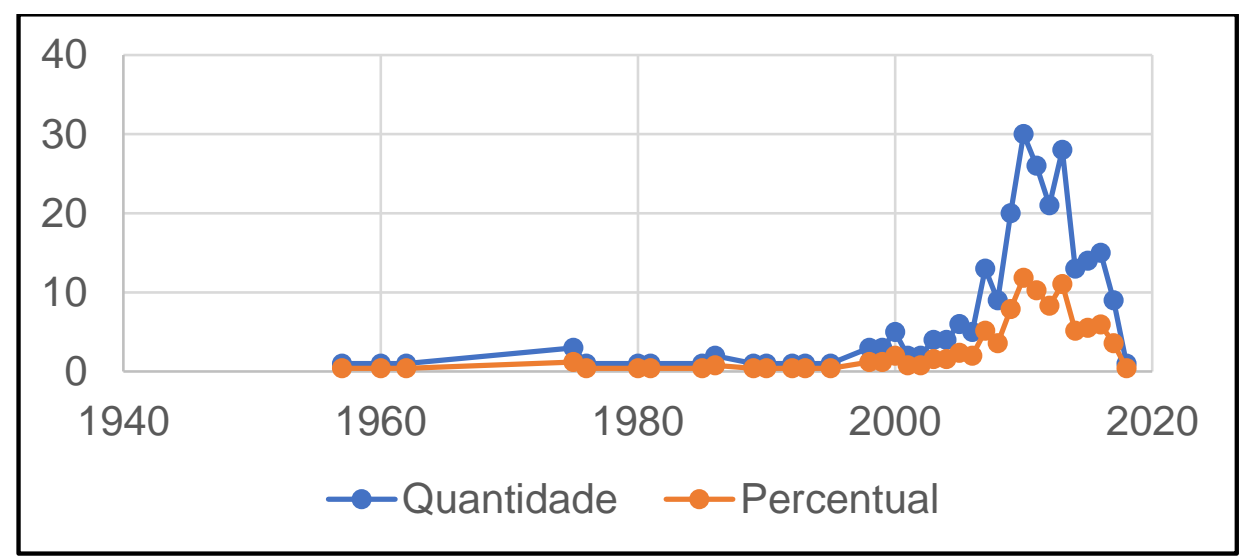

Figura 4: Distribuição do número de pessoas que iniciaram na atividade de observação de aves ao longo dos anos.

Figure 4: Distribution of the number of people who started birdwatching over the years.

Fonte: Elaborado pelos autores (2021).

Source: Elaborated by the authors (2021).

Muitos entrevistados, 40,3\% precisamente, ao serem indagados sobre qual elemento motivador os encaminhou para a atividade, revelaram que foi a busca por maior contato com a natureza, seguida do interesse pela fotografia, $28,1 \%$. Apenas $5,1 \%$ dos respondentes se disseram motivados pela preocupação com a conservação da biodiversidade. No entanto, quando os observadores foram indagados se, além de observar e fotografar aves, havia interesse também em conhecer a biologia/ecologia das espécies avistadas, quase a totalidade respondeu que havia tal interesse. Dos entrevistados, $42,7 \%$ disseram que buscam informações na literatura científica sobre as espécies e outros $28 \%$ em documentários de vida animal.

De acordo com as respostas, pelos menos metade dos observadores de aves procura se envolver noutras atividades esportivas ou culturais quando viaja. Eles mencionaram que também têm interesse em conhecer algo sobre a história/geografia local (20,7\%), acampar (9,2\%), fazer "tracking"|"jogging"|“hiking" (6,8\%), ciclismo $(4,4 \%)$ e pesca esportiva $(2,8 \%)$.

\section{Potencial turístico da atividade de observação de aves}

Os questionários permitiram constatar que pelo menos $50 \%$ dos observadores permanecem na região de 3 a 4 dias, e 35,6\% têm um gasto médio diário entre $R \$$ 150,00 / U\$ 39,00 a R \$250,00 / US \$ 64,00. Pouco mais de $25 \%$ dos observadores que permanecem este tempo na região chegam a gastar, por dia, uma média de até $R \$ 400,00$ / U\$ 103,00 e 15\% ultrapassam esta quantia. Nas despesas diárias, não estão consideradas aquelas relacionadas com o deslocamento até a região, portanto dizem respeito principalmente à hospedagem e à alimentação.

Quando decidem fazer observação de aves na região, mais da metade dos respondentes informa que se vale da internet na busca de informações, sendo que $36,4 \%$ utilizaram a plataforma WikiAves nas suas pesquisas. O percentual de observadores que consultou "amigos", para obter informações antes da viagem, também tem certa expressão, quase $21 \%$, um pouco menos dos que utilizaram a internet para planejar a viagem, $25 \%$. O percentual de observadores que, na última vez em que visitou o parque, se utilizou dos serviços de uma operadora de turismo não passou de $8 \%$, porém, $68,4 \%$ dos observadores contrataram um guia em pelo menos em uma das visitas que fizeram à região. 
Os guias foram acessados através de várias maneiras: indicação dos hotéis, dos funcionários do Parque Nacional da Lagoa do Peixe, de amigos ou localizados na web. Para conhecer a fidelidade dos entrevistados ao Parque Nacional da Lagoa do Peixe, enquanto sítio de importância para a observação de aves, indagamos sobre possível retorno e $74,2 \%$ deles disseram que pretendiam retornar à região nos próximos dois anos.

\section{Impacto potencial da observação de aves}

Pelo menos 139 entrevistados (55\%) informaram que quando visitaram o Parque Nacional da Lagoa do Peixe o interesse não recaiu sobre uma espécie apenas. Os demais confirmaram, sim, que viajaram à região visando encontrar determinada espécie, porém as respostas não demonstraram haver preferência por uma única espécie de ave.

Foi indagado quanto ao emprego do playback para atrair determinado espécime. O playback é uma técnica na qual o canto da ave é reproduzido em campo, eletronicamente ou não, a fim de atraí-la com vistas a obter fotos ou até mesmo uma garantida visualização com mais proximidade. Noventa e nove observadores $(39,1 \%)$ responderam que não se utilizam do recurso, e 73 (28,9\%) informaram que sempre adotam "playback" nas suas atividades. Pelo menos 74 observadores $(29,2 \%)$ indicaram utilizar o recurso na última visita que fizeram ao Parque Nacional da Lagoa do Peixe.

Os entrevistados, em maioria, não se mostraram contrários à adoção de regulamentos que normatizem a observação de aves na região e no Parque Nacional da Lagoa do Peixe. Ao contrário, 67\% deles aprovam iniciativas de regulação e apontam aspectos que deveriam receber atenção de futuras normativas. Também indicaram a necessidade de melhorias na infraestrutura local (Quadro 1).

Quadro 1: Sugestões apontadas pelos observadores com vistas à organização da atividade na região.

Frame 1: Suggestions made by the observers concerning the organization of the activity in the region.

\begin{tabular}{|c|c|}
\hline $\begin{array}{c}\text { Sugestões sobre regulamentação da } \\
\text { atividade }\end{array}$ & $\begin{array}{c}\text { Sugestões sobre melhorias para } \\
\text { atender o turismo de observação de } \\
\text { aves }\end{array}$ \\
\hline $\begin{array}{l}\text { Controle de acesso de pessoas e } \\
\text { veículos }\end{array}$ & $\begin{array}{l}\text { Melhoria na estrutura hoteleira e } \\
\text { gastronômica com mais opções }\end{array}$ \\
\hline Controle do acesso de cães & $\begin{array}{l}\text { Melhoria nas condições de rodovias e } \\
\text { demais acessos }\end{array}$ \\
\hline $\begin{array}{l}\text { Controle do avanço da agricultura, } \\
\text { pecuária, pesca, silvicultura }\end{array}$ & Oferta de aluguel de veículos tracionados \\
\hline Normatização para o uso de playback & $\begin{array}{l}\text { Programação variada de eventos } \\
\text { artísticos/culturais na região }\end{array}$ \\
\hline Maior fiscalização no entorno do Parque & $\begin{array}{l}\text { Criação de um Centro de Recepção aos } \\
\text { visitantes/observadores }\end{array}$ \\
\hline $\begin{array}{l}\text { Utilização de pequenas embarcações na } \\
\text { Lagoa do Peixe }\end{array}$ & $\begin{array}{l}\text { Divulgação de informações sobre as } \\
\text { aves da região }\end{array}$ \\
\hline Criação de roteiro auto guiável & $\begin{array}{l}\text { Estímulo e qualificação para os guias } \\
\text { locais }\end{array}$ \\
\hline & Sinalização nas trilhas \\
\hline
\end{tabular}

Fonte: Elaborado pelos autores (2021).

Source: Elaborated by the authors (2021). 


\section{Discussão}

A taxa de retorno dos questionários ultrapassou a marca dos $45 \%$. Trata-se de um percentual idêntico, em alguns casos até maior, do que as médias encontradas em estudos que se utilizam deste recurso para investigar determinados grupos sociais (BUMGARDNER et al., 2017; FOX et al., 1988; KANUK; BERENSON,1975). Portanto, a amostra deste estudo é consistente e representativa.

Assim como encontrado na literatura, $40 \%$ dos respondentes revelaram que a busca de um contato mais estreito com a natureza é um dos fatores que estimulam a observação de aves. Na Austrália, uma pesquisa em quatro parques nacionais, com - objetivo de reunir informações sobre o uso público, constatou que $61 \%$ dos entrevistados, ao visitarem os parques, querem prioritariamente apreciar a paisagem natural (WEBER; ANDERSON, 2010). Essa preferência coincide com os entrevistados deste estudo, uma vez que também encontramos aqui respostas semelhantes.

Sabe-se que o "birdwatching" já é uma atividade consolidada em países como Reino Unido, Canadá, Austrália e Estados Unidos. Connell (2009) sugere que o número de observadores vem aumentado por conta de uma maior conscientização ambiental, o envelhecimento da população, os estilos de vida mais saudáveis e o apelo a um passatempo que pode ser cerebral e competitivo, como constatado na Austrália.

No Brasil, o "birdwatching" é uma atividade com grande potencial, considerando que o país está entre os que possuem maior biodiversidade no mundo, mas ainda incipiente, e logo trata-se de um segmento com grande possibilidade de expansão. Entre as áreas protegidas no Brasil, o Parque Nacional da Lagoa do Peixe possui os atributos biológicos que definem um bom destino de observação de aves, visto que é uma área de forrageamento de aves migratórias, recebendo diferentes espécies além das residentes.

O perfil dos entrevistados que visitaram o Parque Nacional da Lagoa do Peixe demonstrou que existe correspondência com o perfil dos observadores de aves no mundo. De acordo com o descrito por Connell (2009), os observadores de aves são em sua maioria do sexo masculino, de meia idade (entre 40 e 60 nos) e com bom nível de instrução (ensino superior ou mais). Mesmo com uma década de diferença, o perfil encontrado por esta pesquisa foi o mesmo descrito por Connell (2009).

Considerando a faixa etária, a renda e o grau de instrução dos respondentes, podemos inferir que são pessoas já estabelecidas profissionalmente, com situação financeira estável e com padrão cultural e de instrução altos. Em sua maioria, estão no mercado de trabalho ou já aposentados, etapa da vida que permite investir mais em atividades de lazer. Portanto, percebe-se que o segmento do turismo de observação de aves atrai uma faixa social abastada, de modo que esse público pode contribuir no desenvolvimento econômico da região visitada e, assim, criar oportunidades para diferentes setores na cadeia produtiva do turismo de observação de aves.

Nos municípios que abrangem o Parque Nacional da Lagoa do Peixe, a atividade de observação de aves ganhou impulso na última década. Dados da pesquisa demonstram que o incremento no número de praticantes se deu na mesma época, sendo entre 2008 e 2013 o período em que mais pessoas se iniciaram na atividade. 
Para uma área ser referência nesta categoria de turismo, não basta apenas a "vocação turística" do "birdwatching", com diversidade biológica. São necessários investimentos em infraestrutura, valorização e preservação ambiental, formação de guias, conhecimento das espécies e envolvimento da comunidade, para citar apenas aspectos mais prementes.

Os entrevistados apontaram a falta de infraestrutura nas duas cidades que abrigam o território do Parque Nacional da Lagoa do Peixes, Mostardas e Tavares. Segundo eles, existe carência em relação aos serviços nos municípios (restaurantes, hotelaria) e também em relação aos aspectos da atividade em si, como a falta de demarcação das trilhas, informações sobre as espécies de aves presentes, guias e receptivos. Muitas foram as sugestões e as queixas apresentadas, mas o sentido geral demonstrou que os observadores de aves entendem que o segmento turístico, na região, carece de investimentos. Ao relacionar as sugestões recebidas com os dados formais de orçamento voltado ao turismo, observa-se divergência entre a satisfação dos visitantes e o serviço disponível.

Se feita a comparação de renda, constata-se que a maioria dos observadores de aves (69\%) tem renda mensal significativamente superior (acima de $R \$ 6.000,00$ / US $\$ 1.500,00)$ à média de salário dos moradores da região (IBGE) que, na data utilizada como referência neste estudo, abril de 2019, correspondia a $R \$ 1.896,20$ (US $\$ 490,20)$. Essa diferença de três vezes mais renda demonstra que os visitantes têm um potencial de consumo que a estrutura local não está preparada para atender. As informações obtidas juntos aos observadores de aves deixa claro que a rede hoteleira poderia estar mais bem preparada para este segmento turístico. É possível estabelecer que os observadores de aves em questão, que possuem alto grau de instrução e renda, tendem a ser exigentes em seus hábitos de consumo. Considerando os entrevistados, $79 \%$ são originados das regiões Sul e Sudeste do país. Não por acaso, essas duas regiões contribuíram com $70 \%$ do Produto Interno Bruto (PIB), no ano de 2016.

A pesquisa também apontou que observadores de aves, ao viajarem, envolvem-se em outras atividades. Dos respondentes, $20 \%$ informaram se interessar por conhecer aspectos da história e geografia local, o que é oferecido pela região do Parque, de colonização açoriana, que possui atrativos turísticos para atender o interesse demonstrado na pesquisa. Em 2010, uma lei municipal reconheceu o Patrimônio Imaterial do Município de Mostardas, promovendo a valorização da cultura local. Embora com diferentes atrativos turísticos, a população residente nos municípios de Mostardas e Tavares considera o Parque Nacional da Lagoa do Peixe o principal atrativo da região (TEIXEIRA, 2014).

No Parque Nacional da Lagoa do Peixe, observadores de aves têm a expectativa de encontrar o maior número possível de espécies, mas $45 \%$ dos entrevistados apontaram o interesse em apenas uma determinada espécie responsável pelo deslocamento até a região. Existe um interesse pulverizado sobre as espécies de onde se conclui que não há assédio sobre determinada espécie. Entretanto, $60 \%$ dos observadores informam que em algum momento se utilizaram do "playback.

Conforme Sekercioglu (2002), os impactos da perturbação do "birdwatching" são complexos, com respostas diferentes entre espécies, entre indivíduos da mesma espécie e até mesmo entre períodos diferentes para os mesmos indivíduos. Para minimizar os possíveis impactos, o autor sugere aderir e insistir na conduta ética da 
atividade, minimizando o impacto negativo nas aves, o que inclui ser cuidadoso com espécies ameaçadas ou quase ameaçadas, insistir em guias certificados e criticar qualquer ação imprópria na atividade. Ao minimizar a perturbação da vida selvagem, mantém-se o habitat preservado, garantindo a presença contínua de aves a serem observadas.

\section{Conclusão}

Este estudo apresentou resultados que poderão subsidiar discussões, tanto no setor público quanto na iniciativa privada a respeito da implantação de uma cadeia turística a partir da atividade de observação de aves. Foi possível verificar que o turismo de observação de aves não está organizado na região, sendo necessário investimentos para atender o potencial da atividade.

O trabalho também mostrou, de maneira inequívoca, que o "birdwatching" tem peso econômico capaz de alavancar o turismo na região do Parque Nacional da Lagoa do Peixe, gerando empregos e renda. Foi ainda possível elencar, a partir das informações vindas dos observadores de aves, quais as deficiências que precisam ser sanadas para melhor atender os turistas.

A respeito da pressão da atividade sobre as espécies, os dados desta pesquisa não foram suficientes para determinar o impacto da observação de aves sobre as espécies, dependendo assim, de estudos mais direcionados ao tema, a fim de que se comprove sua sustentabilidade, sem oferecer riscos às aves que são foco das observações.

Cabe ressaltar que a área do parque tem uma importância especial para a conservação da biodiversidade, tendo em vista ser uma região que recebe anualmente milhares de aves migratórias, além da riqueza local. Logo, a região, se bem divulgada, atrairá mais visitantes, gerando renda, incremento econômico e oportunizando o crescimento da comunidade local.

\section{Referências}

ALMEIDA, M.P.S.R.; BAHIA, M.C.; NELSON, S.P. Observação de aves no Refúgio de Vida Silvestre Metrópole da Amazônia: uma contribuição para a conservação ambiental da unidade e ao desenvolvimento turístico do Estado do Pará. Revista Brasileira de Ecoturismo, São Paulo, v.9, n.3, ago/out 2016, p.544-574.

ARIZPE C. O.; URCIAGA, J.; ARIZPE-V., A. Tourism in natural protected areas in Mexico. WIT Transactions on Ecology and the Environment, v.179, p.1117-1126, 2013. DOI: $10.2495 /$ SC130952

BALMFORD A.; GREEN, J. M. H.; ANDERSON, M.; BERESFORD, J.; HUANG, C.; NAIDOO, R. et al. Walk on the Wild Side: Estimating the Global Magnitude of Visits to Protected Areas. PLoS Biol, v.13, n. 2. 2015. DOI: 10.1371/journal.pbio.1002074

BFN. Federal Agency for Nature Conservation. Tourism Development in protected areas. 2020. Disponível em: <https://www.bfn.de/en/activities/tourism-andsports/tourism/tourism-and-protected-areas.html>. Acesso em: 31 ago. 2020.

BUMGARDNER, M.; MONTAGUE, I.; WIEDENBECK, J. Survey response rates in the forest products literature from 2000 to 2015. Wood and Fiber Science, v. 49, n. $1,2017$. 
Cl. Conservação Internacional. Observação de aves une instituições em nova plataforma turística para o sul da Bahia. 2017. Disponível em: $<$ https://www.conservation.org/brasil/noticias/2019/10/18/observação-de-aves-uneinstituições-em-nova-plataforma-turística-para-o-sul-da-bahia>. Acesso em: 28 out. 2019.

CONNELL, J. Birdwatching, twitching and tourism: Towards an Australian perspective. Australian Geographer, v. 40, n. 2, p. 203-217, 2009.

DEPARTMENT OF AGRICULTURE, WATER AND THE ENVIRONMENT. Australia's protected areas. 2019. Disponível em: $<$ https://www.environment.gov.au/land/nrs/about-nrs/australias-protected-areas $>$. Acesso em: 05 out. 2020.

DIAS, R., FIGUEIRA, V. O turismo de observação de aves: Um estudo de caso do município de Ubatuba/SP-Brasil. Tékhne: Revista de Estudos Politécnicos Polytechnical Studies Review, v. 8, n.14, p. 85-96, 2010.

EAGLES, P. F.; MCCOOL, S. F.; HAYNES, C. D.; PHILLIPS, A. Sustainable tourism in protected areas: Guidelines for planning and management. IUCN Gland, Switzerland and Cambridge, UK. 2002.

FOX, R. J.; CRASK, M. R; KIM, J. Mail survey response rate a meta-analysis of selected techniques for inducing response. Public Opinion Quarterly, v. 52, n. 4, p. 467-491, 1988.

FWS. Fish and Wild Service. Birding in the United States: A Demographic and Economic Analysis. $2013 . \quad$ Disponível em: $<$ https://www.fws.gov/southeast/pdf/report/birding-in-the-united-states-ademographic-and-economic-analysis.pdf >. Acesso em: 03 set. 2020.

GORINI, A. P. F.; MENDES, E. F.; CARVALHO, D. M. P. Concessão de serviços e atrativos turísticos em áreas naturais protegidas: o caso do Parque Nacional do Iguaçu, BNDES Setorial, Rio de Janeiro, n. 24, p. 171-209, 2006.

GUADAGNIN, D. L.; PETER, A. S.; PERELLO, L. F. C.; MALTCHIK, L. Spatial and temporal patterns of waterbird assemblages in fragmented wetlands of southern Brazil. Waterbirds, v. 28, n. 3, p. 261-272, 2005.

IBGE. Instituto Brasileiro de Geografia e Estatística. População. 2017. Disponível em: $<$ https://cidades.ibge.gov.br/brasil/rs/tavares/panorama $>$. Acesso em: 01 set. 2019.

KANUK, L.; BERENSON, C. Mail Surveys and Response Rates: A Literature Review. Journal of Marketing Research, v. 12, n. 4, p. 440-453, 1975.

LAMAS, I. R.; MOREIRA-LIMA, L.; SILVA, T. C. L. Observação de aves na costa do descobrimento: educação, conservação e sustentabilidade. Rio de Janeiro: Conservação Internacional. $2018 . \quad$ Disponível em: $<$ https://www.icmbio.gov.br/portal/images/stories/biodiversidade/UCRPPN/Livro aves Descobrimento.pdf> Acesso em: 22 mar. 2021.

MCCOOL, S. F. Constructing partnerships for protected area tourism planning in an era of change and messiness. Journal of Sustainable Tourism, v.17, n. 2, p. 133148, 2009.

MTUR. Ministério do Turismo. Atrativos naturais e ecoturismo atraem cada vez mais estrangeiros ao Brasil. 2016. Disponível em: $<$ http://antigo.turismo.gov.br/\%C3\%BAltimas-not\%C3\%ADcias/6511-atrativos- 
naturais-e-ecoturismo-atraem-cada-vez-mais-estrangeiros-ao-brasil.html>.

Acesso em 01 set. 2020.

MTUR. Ministério do Turismo. OMT lança diretrizes globais para a reabertura do turismo. 2020. Disponível em: <http://antigo.turismo.gov.br/\%C3\%BAltimasnot\%C3\%ADcias/13534-omt-lan\%C3\%A7a-diretrizes-globais-para-a-reabertura-doturismo.html>. Acesso em: 30 ago. 2020.

MTUR. Ministério do Turismo. Relatório de Impacto da Pandemia de COVID-19 nos setores de turismo e cultura no Brasil. 2019. Disponível em: <http://www.dadosefatos.turismo.gov.br/boletins.html>. Acesso em: 01 set. 2020.

PATA. Pacific Travel Association. Growth in international arrivals into Asia Pacific strong in 2018. 2019. Disponível em: <https://www.pata.org/growth-in-internationalarrivals-into-asia-pacific-strong-in-2018/>. Acesso em: 28 out. 2019.

PICKERING, C.; ROSSI, S. D.; HERNANDO, A.; BARROS, A. Current knowledge and future research directions for the monitoring and management of visitors in recreational and protected areas. Journal of Outdoor Recreation and Tourism, v. 21, p.10-18, 2018.

PINHEIRO R. T. Turismo de observação de aves nas Unidades de Conservação da região da llha do Bananal, Cantão (TO). Revista Brasileira de Ecoturismo, v.12, n.4, p.400-433, 2019.

SEBRAE. Serviço Brasileiro de Apoio às Micro e Pequenas Empresas. Turismo de observação de aves. 2018. Disponível em: $<$ https://sebraeinteligenciasetorial.com.br/produtos/boletins-de-tendencia/turismo-deobservacao-de-aves/5bfd8072d4f78d1a00f95fc7\#download>. Acesso em: 19 set. 2020.

SEKERCIOGLU, C. H. Impacts of birdwatching on human and avian communities. Environmental Conservation, v. 29, n. 3, p. 282-289, 2002. DOI: 10.1017/S0376892902000206

SEMEIA. Turismo em parques nacionais e a conservação da natureza. 2015. Disponível em: $<$ http://www.semeia.org.br/admuploads/uploads/Novembro 2 Turismo Parques Na cionais conservacao Biodiversidade final.pdf>. Acesso em: 28 out. 2019.

SILVA, J. A. D. Birdwatching como uma proposta de valorização do espaço ecoturístico da Lagoa Rodrigo de Freitas, Rio de Janeiro (RJ). Revista Brasileira de Ecoturismo, v, 13, n.3, p. 587-599, 2020.

SILVA-MELO, M. R.; MELO, G. A. P.; GUEDES, N. M. R. Turismo Sustentável: alternativa para o desenvolvimento da APA Baia Negra, Pantanal de Mato Grosso do Sul. Revista Brasileira de Ecoturismo, v. 12, n. 5, 2019.

SPAOLONSE, E.; MARTINS, S. S. O. Ecoturismo: uma ponte para o turismo sustentável. Revista Brasileira de Ecoturismo, v.9, n.6, p. 684-698, 2017.

STEVEN R.; JONES D. Bird-watching tourism. In: Jafari J., Xiao H. (Eds.). Encyclopedia of Tourism. Springer, Cham. 2014.

TEIXEIRA, P. R. A visão da população de Mostardas e Tavares-RS sobre a contribuição do turismo no Parque Nacional da Lagoa do Peixe ao desenvolvimento local. 2014. 100f. Universidade de Caxias do Sul. Dissertação (Mestrado). Caxias do Sul, 2009. 
TIES. The Internacional Ecoturism Society. Ecotourism is the solution to overtourism. 2019. Disponível em: <https://ecotourism.org/news/ecotourism-is-thesolution-to-overtourism/>. Acesso em: 12 ago. 2020.

TIES. The International Ecotourism Society. Ecotourism statistical fact sheet. 2000. Disponível em: <http://www.active-tourism.com/factsEcotourism1.pdf>. Acesso em: 10 out. 2019.

TIES. The International Ecoturism Society. What is ecotourism?. 2015. Disponível em: <https://ecotourism.org/what-is-ecotourism/>. Acesso em: 10 out. 2019.

TOMAZELLI, L.; VILLWOCK, J. Geologia do sistema lagunar holocênico do Litoral Norte do Rio Grande do Sul. Pesquisas em Geociências, v.18, n.1, p.1-13, 1991.

UNTWO. World Turism Organization. Solid growth in international arrivals in January-September 2019, though uneven across regions. 2020. Disponível em: $<$ https://www.e-unwto.org/doi/pdf/10.18111/wtobarometereng.2019.17.1.4>. Acesso em: 30 ago. 2020.

VALADARES, C. Turismo de observação de aves ganha adeptos no Brasil. Ministério do Turismo, [s.l.], 19 set. 2016. Disponível em: $<$ https://www.gov.br/turismo/pt-br/assuntos/ultimas-noticias/turismo-de-observacaode-aves-ganha-adeptos-no-brasil> Acesso em: 01 set. 2019.

WEBER, D.; ANDERSON, D. Contact with Nature: Recreation experience preferences in Australian parks. Annals of Leisure Research, v. 13, n. 1-2, p. 46-69, 2010.

WIKIAVES. 2020. Site de conteúdo interativo, direcionado à comunidade brasileira de observadores de aves. Página inicial. Disponível em: <https://www.wikiaves.com.br/index.php >. Acesso em: 02 set. 2020.

Silvia Maria Kaiser: Universidade dos Açores, Horta, Territorio Autonomo dos Açores, Portugal.

E-mail: silkais@terra.com.br

Link para o currículo Lattes: http://lattes.cnpq.br/8248073334777102

João Manuel dos Anjos Gonçalves: Universidade dos Açores, Horta, Territorio Autonomo dos Açores, Portugal.

E-mail: joao.ma.goncalves@uac.pt

Link para o currículo Lattes: https://orcid.org/0000-0001-7717-658X

Luís Fernando Carvalho Perelló: Universidade Federal de São Carlos, São Carlos. SP, Brasil.

E-mail: Ifperello@yahoo.com.br

Link para o currículo Lattes: http://lattes.cnpq.br/7358580565148566

Data de submissão: 11 de abril de 2021

Data de recebimento de correções: 14 de outubro de 2021

Data do aceite: 14 de outubro de 2021

Avaliado anonimamente 